\title{
Carbon and Hydrogen Accumulation on Exhaust Duct in LHD*)
}

\author{
Kazunari KATAYAMA, Naoko ASHIKAWA ${ }^{1)}$, Keiichiro UEHARA and Satoshi FUKADA \\ Interdisciplinary Graduate School of Engineering Science, Kyushu University, \\ 6-1 Kasugakoen, Kasuga-shi, Fukuoka 816-8580, Japan \\ 1) National Institute for Fusion Science, 322-6 Oroshi-cho, Toki 509-5292, Japan
}

(Received 25 November 2014 / Accepted 8 March 2015)

\begin{abstract}
To consider carbon balance and hydrogen isotope balance in the fuel cycle system and tritium safety management of a fusion reactor, the evaluation of carbon and hydrogen isotope accumulation not only in the vacuum vessel but also in the exhaust system is necessary. In the present work, type 316 stainless steel substrates were installed at 4 locations in the exhaust duct of the Large Helical Device (LHD) during the 13th experimental campaign. By using the combustion method, the amount of carbon slightly adhering to the substrates, which cannot be measured by electric microbalances, was successfully quantified to be $2 \mu \mathrm{g} / \mathrm{cm}^{2}$. The hydrogen release behavior from the substrate was consistent with that from carbon deposition layer formed by hydrogen plasma sputtering. $\mathrm{H} / \mathrm{C}$ ratio on the substrate was estimated to be about 1-1.5. Hydrogen incorporated into the metal deposit formed from type 316 stainless steel in the sputtering-deposition device in the laboratory can remain in the deposit even under high vacuum condition in the exhaust duct for a long period.
\end{abstract}

(C) 2015 The Japan Society of Plasma Science and Nuclear Fusion Research

Keywords: carbon accumulation, hydrogen isotope accumulation, exhaust duct

DOI: $10.1585 /$ pfr. 10.3405039

\section{Introduction}

In a fusion reactor on which graphite materials are used as plasma facing material, carbon deposition layer including hydrogen isotopes is formed on the plasma facing wall. Sticking coefficients for several kinds of hydrocarbon radical, which are generated by chemical erosion of graphite, have been evaluated by laboratory experiments $[1,2]$. The hydrocarbon radicals having a large sticking coefficient would be deposited widely in the plasma confinement vessel, but ones having a small sticking coefficient may be transferred to the exhaust system. In JET, carbon flakes including tritium of about $1 \mathrm{TBq} / \mathrm{g}$ accumulated at the louvres, which are installed to protect cryopumps, in a region shadowed from plasma [3]. This suggests that a certain amount of hydrocarbon and hydrocarbon radical with tritium were transported to vacuum pumps via the exhaust duct. Investigations of carbon deposition and hydrogen accumulation in the plasma confinement vessel of fusion experimental devises such as LHD [4-7] and JT60 [8,9] has been performed. However, the understanding of carbon and hydrogen transport to the exhaust system is insufficient.

In a fusion reactor, gaseous hydrocarbon can be processed in fuel purification system but carbon with tritium adhering on the metal wall of the vacuum component and duct will be continuously accumulated in the exhaust system during the operation. Although the amount of accu-

author'se-mail: kadzu@nucl.kyushu-u.ac.jp

*) This article is based on the presentation at the 24th International Toki Conference (ITC24). mulated carbon on the metal walls in the exhaust system is speculated to be significantly smaller than that in the plasma confinement vessel, the estimation of the amount of carbon and hydrogen adhering there is important for the evaluation of carbon balance and hydrogen isotope balance in the fusion reactor system and tritium safety management in a maintenance of the exhaust system.

In the present work, in order to understand carbon and hydrogen accumulation behavior in the exhaust duct of the fusion experimental devices, stainless steel (SS316) substrates were mounted in the exhaust duct of LHD, in which graphite material is used in divertor region and SS316 is used in first wall, during the 13th experimental campaign. It has been reported by the present authors that metal deposit formed from stainless steel by hydrogen plasma sputtering can retained a large amount of hydrogen during deposition process [10]. In order to confirm whether hydrogen isotopes co-deposited with metals remain in the deposit for a long time under high vacuum condition of LHD exhaust duct, metal deposit were preliminarily formed on some of SS316 substrates by hydrogen plasma sputtering of a stainless steel plate. This information would be useful for analyzing hydrogen isotope retention in the metallic dust transported to the exhaust duct during the experiment in LHD. After the campaign, the substrates were dismounted from LHD and hydrogen release from the substrate was observed by thermal desorption spectroscopy (TDS) method. Additionally, the amount of carbon adhering on the substrate was roughly estimated by combustion method. 


\section{Experimental}

\subsection{Sample location}

SS316 substrates, $10 \mathrm{~mm} \times 10 \mathrm{~mm}$ in size, $1 \mathrm{~mm}$ in thickness, with and without metal deposit formed from SS316 were respectively mounted on the sample holder fixed on the duct wall. The location of the exhaust duct is shown in Fig. 1. To understand the approximate tendency of carbon adhesion distribution, the sample holders were fixed on 4 locations that are different distance or direction from the vacuum chamber as shown in Fig. 2. Sample holder P1 and P2 were fixed at port A, P3 was fixed at port $\mathrm{B}$ and P4 was fixed at port C. Two bare SS316 substrates and two metal deposited substrates were set in each sample holder. 4 substrates can be mounted in one holder for the present study. A picture of the sample holder P3 fixed on the duct wall is shown in Fig. 3.

\subsection{Preparation of metal deposit}

Metal deposits were formed on the SS316 substrates by hydrogen plasma sputtering by using the capacitively coupled radio frequency (RF) sputtering device which has been shown in the previous paper [11]. A type 316 stainless steel plate, $50 \mathrm{~mm} \times 50 \mathrm{~mm}$ in size, $1 \mathrm{~mm}$ in thickness and $99.5 \%$ in purity, (Nilaco Co.), was mounted on the RF electrode as a target. Several SS316 substrate were mounted on the ground electrode. After mounting SS316 substrates, the plasma chamber was evacuated by a vacuum pump and pure hydrogen gas introduced via a mass flow controller. Hydrogen gas pressure was set to be $10 \mathrm{~Pa}$. RF power was controlled in the range from $150 \mathrm{~W}$ to $200 \mathrm{~W}$ with $13.56 \mathrm{MHz}$. The sputtering-deposition process was continued for $107 \mathrm{~h}$. Substrate temperature was $110^{\circ} \mathrm{C}$ on average.

For instance, SS316 substrates with and without metal deposit mounted on the holder P1 were named as P1dep1, $\mathrm{P} 1 \mathrm{dep} 2, \mathrm{P} 1 \mathrm{ss} 1$ and P1ss2, respectively.

\subsection{Analysis of SS substrate installed in LHD}

Surface observation by a scanning electron microscope (SEM) and elemental analysis by an energy dispersive X-ray spectrometry (EDX) were carried out. Raman spectroscopy was performed for sample P2ss1 to investigate chemical-bonding state of carbon adhering to the substrate. However, a significant signal was not obtained because of a small amount of carbon.

TDS measurements were carried out for P3ss1, $\mathrm{P} 3$ dep1, P4ss 1 and $\mathrm{P} 4 d e p 1$ with a ramping rate of $1^{\circ} \mathrm{C} / \mathrm{s}$. In order to discuss hydrogen release behavior from the SS316 substrate dismounted from LHD, deuterium release behaviors from metal deposit and carbon deposit were investigated by TDS method. The metal deposit (sample MD) was formed on a tungsten foil substrate from type 316 stainless steel by deuterium plasma sputtering in the same sputtering device used for LHD sample. Deuterium gas

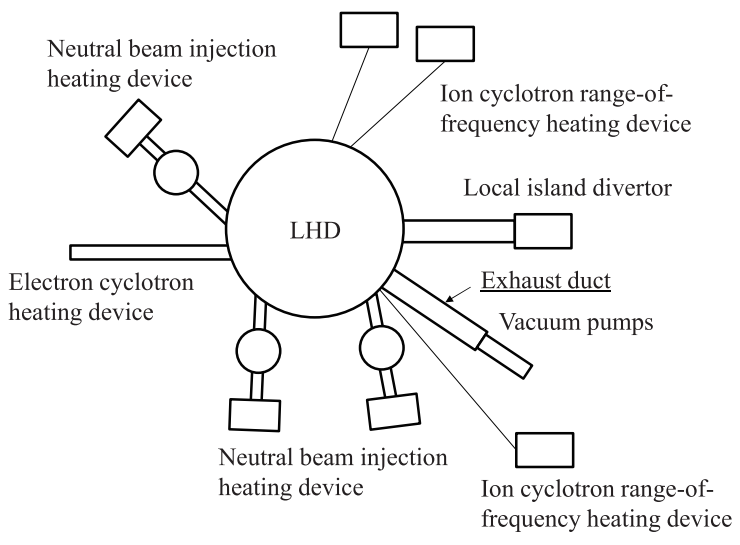

Fig. 1 The location of the exhaust duct.

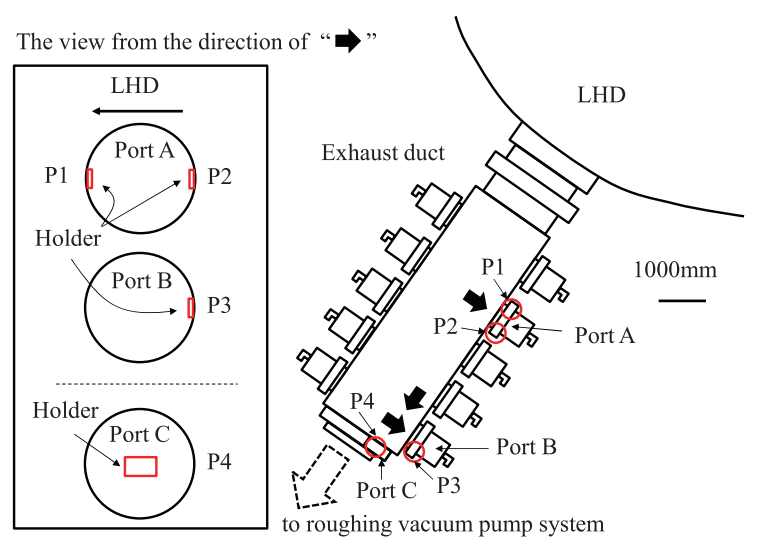

Fig. 24 locations of the sample holders in exhaust duct.

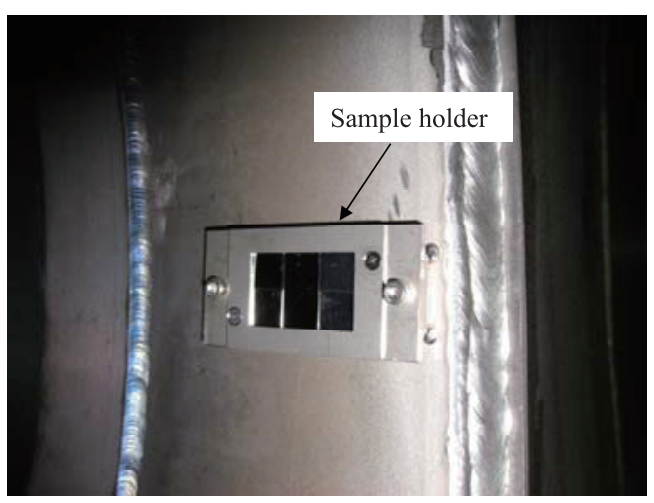

Fig. 3 A picture of the sample holder P3 fixed on the duct wall.

pressure was set to be $10 \mathrm{~Pa}$. RF power was controlled to be $100 \mathrm{~W}$ with $13.56 \mathrm{MHz}$. The sputtering-deposition process was continued for $130 \mathrm{~h}$. Substrate temperature was about $100^{\circ} \mathrm{C}$. The carbon deposit was formed on quartz substrates from isotropic graphite IG430U mainly by chemical sputtering with deuterium plasma in the other sputtering device. The sputtered carbon is basically deposited as hydrocarbon radicals. Deuterium gas pressure was set to be $20 \mathrm{~Pa}$. RF power was controlled to be $200 \mathrm{~W}$ with $13.56 \mathrm{MHz}$. One quartz substrate (sample CD1) was 
mounted on the center of the ground electrode, where deuterium ion flux is relatively high and the temperature was about $100^{\circ} \mathrm{C}$. Another quartz substrate (sample CD2) was mounted on the vicinity of the chamber wall, where deuterium ion flux is quite low and the temperature was a few $10^{\circ} \mathrm{C}$.

\subsection{Combustion experiment}

Weight of each SS316 substrates before and after installation in LHD was measured by an electronic balance with a sensitively of $10 \mu \mathrm{g}$. However, weight change was not observed. Therefore combustion method was tried to quantify the amount of carbon adhering to the SS316 substrate.

The schematic diagram of experimental apparatus for combustion experiment is shown in Fig. 4. In order to exclude impurity water vapor in the gas cylinder, an absorbent (MS-5A) bed was equipped in each gas lines. The sample was put into a quartz reaction tube and argon gas including oxygen was introduced. The reaction tube was closed and then heated by an electric furnace. After one hour heating, the reaction tube was opened and pure argon gas was introduced to transport gaseous components to a gas chromatograph (GC:GC-8A, SHIMAZU Co.) with a thermal conductivity detector (TCD).

As preliminary test, carbon deposit, which was prepared by hydrogen sputtering method, was heated in a closed quartz reaction tube with $1 \% \mathrm{O}_{2} / \mathrm{Ar}$ gas at 300, 400, 500 and $600^{\circ} \mathrm{C}$. It was found that $\mathrm{CO}_{2}$ was generated above $500^{\circ} \mathrm{C}$. $\mathrm{P} 1 \mathrm{ss} 2$ and $\mathrm{P} 3 \mathrm{ss} 2$ were first heated in $0.1 \% \mathrm{O}_{2} / \mathrm{Ar}$ gas at $500^{\circ} \mathrm{C}$ for 3 hours and then heated in $0.1 \% \mathrm{O}_{2} / \mathrm{Ar}$ gas at $500^{\circ} \mathrm{C}$ for 1 hour. $\mathrm{P} 4 \mathrm{ss} 2$ was first heated in $1 \% \mathrm{O}_{2} / \mathrm{Ar}$ gas at $500^{\circ} \mathrm{C}$ for 1 hours and then heated in $1 \% \mathrm{O}_{2} / \mathrm{Ar}$ gas at $600^{\circ} \mathrm{C}$ for 1 hour. Two fresh SS316 substrates were heated in each combustion condition in order to obtain the amount

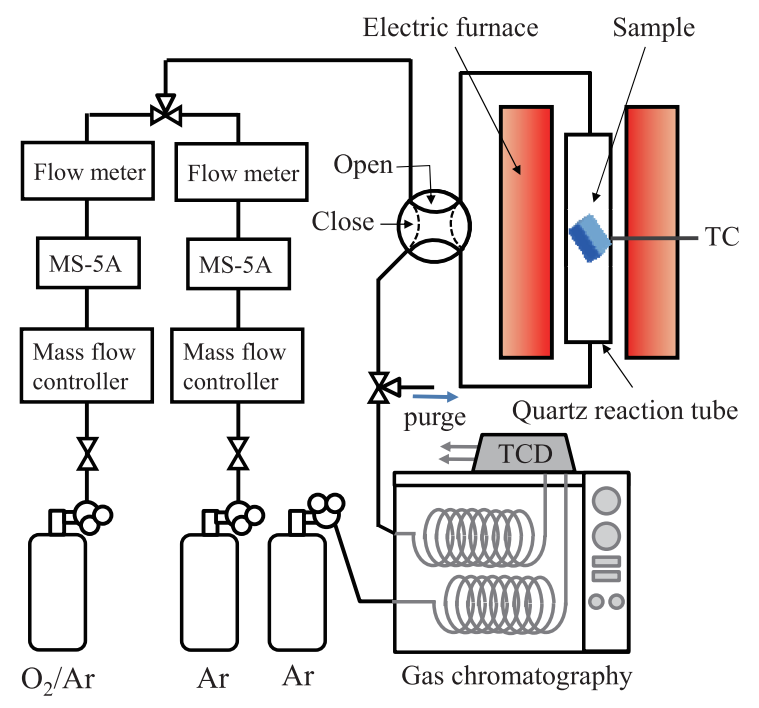

Fig. 4 The schematic diagram of experimental apparatus for combustion experiment. of $\mathrm{CO}_{2}$ generated by the reaction of $\mathrm{SS} 316$ substrate with oxygen.

\section{Results and Discussion}

SEM images for 4 samples without metal deposit are shown in Fig. 5. The clear boundary between the bare region and the edge region which is masked by the holder was observed on each substrate. These indicate the trace of deposition. The atomic ratio on the surface of the bare region for each sample was compared in Fig. 6. On the whole, it was found that approximately $40 \%$ of the elements near the surface are carbon. This indicates that carbon is being approximately uniformly adhering to the metal wall of the duct as gaseous components.

Hydrogen release behaviors from P3ss1, P3dep1, P4ss1 and P4dep1 are shown in Fig. 7 (a). For comparison, $\mathrm{H}_{2}, \mathrm{HD}$ and $\mathrm{D}_{2}$ release behaviors from $\mathrm{MD}, \mathrm{D}_{2}$ release behavior from CD1 and CD2 are shown in Fig. 7 (b) and Fig. 7 (c), respectively. The hydrogen release curves from P3ss1 and P4ss1, P3dep1 and P4dep1 showed relatively same shape. This indicates that hydrogen was being retained in P3ss1 and P4ss1, P3dep1 and P4dep1 under the same situation. In Fig. 7 (b), $\mathrm{HD}$ and $\mathrm{D}_{2}$ release rates were magnified 5 times and 20 times respectively because these were much smaller than $\mathrm{H}_{2}$ release rate. Deuterium release amount from MD was considerably smaller than hy-

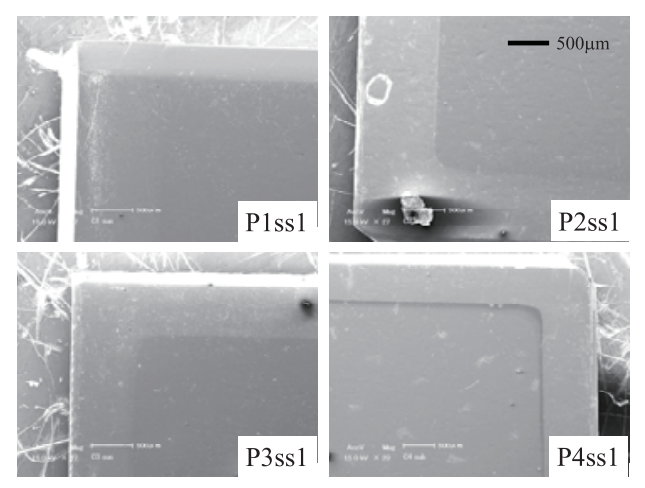

Fig. 5 SEM images of the substrate surface.

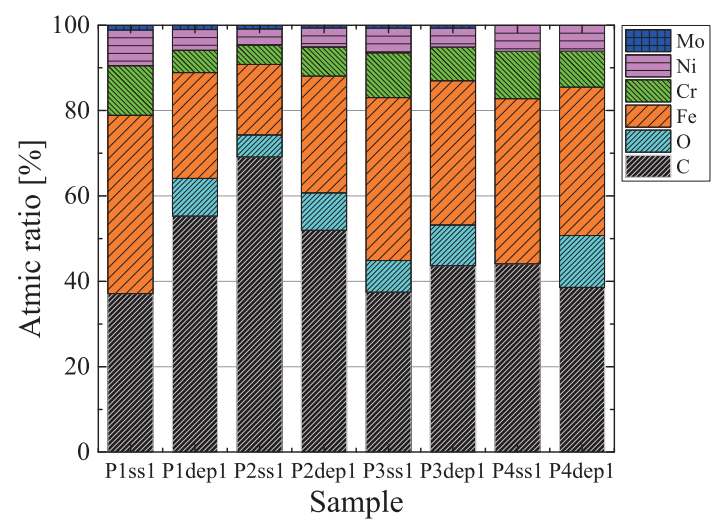

Fig. 6 Atomic ratios on the bare surface of the substrates. 

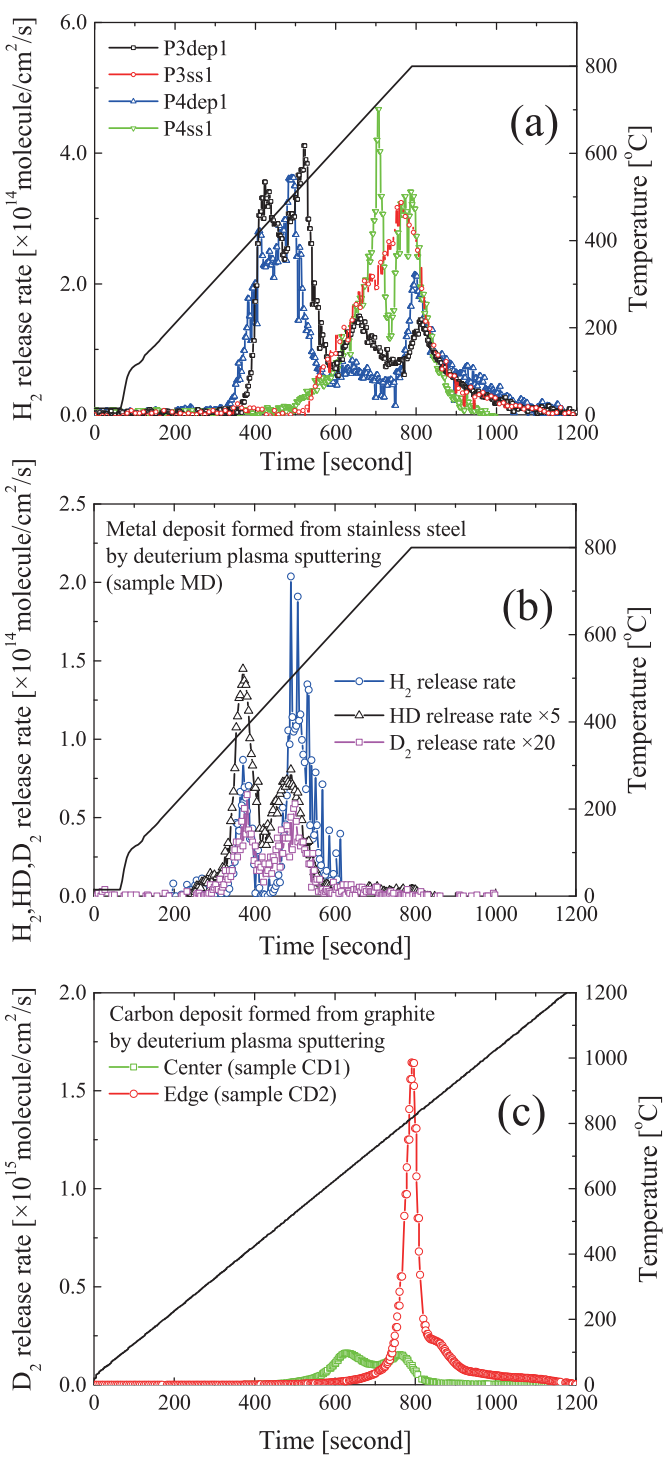

Fig. $7 \mathrm{H}_{2}$ or $\mathrm{D}_{2}$ release behaviors from the samples installed in LHD (a), metal deposit formed from 316SS (b), and carbon deposits formed from graphite (c).

drogen release amount although MD was formed by deuterium plasma sputtering. The similar phenomenon for tungsten sputtering-deposition was discussed in the previous paper but the mechanism is not enough clarified yet [12]. It was found that two release peaks of hydrogen isotopes from $\mathrm{MD}$ appears at $370^{\circ} \mathrm{C}$ and $500^{\circ} \mathrm{C}$. Deuterium release from $\mathrm{CD} 1$ has two broad peaks at $600^{\circ} \mathrm{C}$ and $800^{\circ} \mathrm{C}$. From $\mathrm{CD} 2$, one sharp peak appeared at $800^{\circ} \mathrm{C}$. This suggests that hydrogen isotope retained in carbon deposition is approximately released in the temperature range between $600^{\circ} \mathrm{C}$ and $800^{\circ} \mathrm{C}$, depending on deposition condition. From comparison of release peaks, hydrogen released from P3ss1 and P4ss1 can be concluded to be retained in the carbon adhering to the substrate. The hydrogen release from $\mathrm{P} 3 \mathrm{dep} 1$ and $\mathrm{P} 4 \mathrm{dep} 1$ at the temperature range from $400^{\circ} \mathrm{C}$ to $600^{\circ} \mathrm{C}$ indicates that hydrogen incorporated into metal deposit during the sputtering-deposition process can remain in the deposit under high vacuum con-

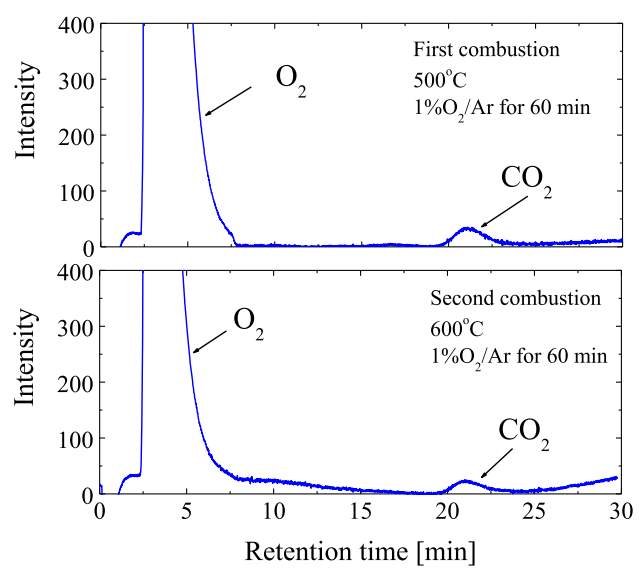

Fig. 8 The signal intensity from a thermal conductivity detector in the gas chromatograph with the retention time for combustion of sample P4ss2.

dition for a long period. The amounts of hydrogen released from P3dep1 and P4dep1 above $600^{\circ} \mathrm{C}$, which is retained in carbon, were smaller than that from P3ss 1 and P4ss 1 . A part of hydrogen released from metal deposit would react with carbon adhering on the metal deposit and be released as hydrocarbon, although signal of $\mathrm{m} / \mathrm{e}=16$ was under the detection limit of a quadruple mass spectrometer because of low sensitivity.

As an example, the change of the signal intensity from TCD with the retention time are shown in Fig. 8, where P4ss2 was heated. A first large peak is attributed to $\mathrm{O}_{2}$ and a second peak is attributed to $\mathrm{CO}_{2}$. For three samples, P1ss2, P3ss2 and P4ss2, the amount of $\mathrm{CO}_{2}$ generated in the second heating was approximately consistent with the amount of $\mathrm{CO}_{2}$ generated by the reaction of fresh SS316 substrate with oxygen. This indicated that almost all carbon adhering to the sample was converted to $\mathrm{CO}_{2}$ in the first heating. From the quantified amount of $\mathrm{CO}_{2}$, the amount of carbon adhering to the surface of $\mathrm{P} 1 \mathrm{ss} 2, \mathrm{P} 3 \mathrm{ss} 2$ and $\mathrm{P} 4 \mathrm{ss} 2$ were estimated to be $1.28,1.73$ and $2.09 \mu \mathrm{g}$, respectively. When it is assumed that carbon is adhered on the bare surface area of the substrate, which is approximately $0.90 \mathrm{~cm}^{2}$, the amounts of carbon per $\mathrm{cm}^{2}$ are $1.42 \mu \mathrm{g} / \mathrm{cm}^{2}$ on P1ss $2,1.92 \mu \mathrm{g} / \mathrm{cm}^{2}$ on P3ss 2 and $2.32 \mu \mathrm{g} / \mathrm{cm}^{2}$ on $\mathrm{P} 4 \mathrm{ss} 2$, respectively. It can be said that about $2 \mu \mathrm{g} / \mathrm{cm}^{2}$ of carbon adhered on the metal wall of LHD exhaust duct during 13th experimental campaign.

The density of hydrogen rich carbon films formed on the remote area of the inner JET divertor has been reported to be about $1.0 \mathrm{~g} / \mathrm{cm}^{3}$ [13]. When the density of carbon adhering to the substrates is assumed to be $1.0 \mathrm{~g} / \mathrm{cm}^{3}$, the thickness of carbon deposition on the SS316 substrates is estimated to be about $20 \mathrm{~nm}$. This value is significantly smaller than the thickness of co-deposited carbon film (the maximum thickness is about $400 \mathrm{~nm}$ ) produced in the vicinity of LHD divertor tiles on the material probe during the 13th experimental campaign [7]. Here, the atomic 
ratio of hydrogen to the other deposited elements (carbon, boron and iron) were shown to be in the range from 0.1 to 0.6. From the estimated amounts of carbon on P3ss2 and $\mathrm{P} 4 \mathrm{ss} 2$, and from the released amount of hydrogen from $\mathrm{P} 3 \mathrm{ss} 1$ and $\mathrm{P} 4 \mathrm{ss} 1, \mathrm{H} / \mathrm{C}$ ratios in the deposit on the duct were obtained to be 1.52 and 1.04, respectively. These values are larger than the $\mathrm{H} / \mathrm{C}$ in co-deposited carbon film produced in the vacuum vessel. This result suggests that the $\mathrm{H} / \mathrm{C}$ in the precursor of the deposit formed in the exhaust duct is higher than that formed in the vacuum vessel. From the rough estimation, the surface area of metal wall in the duct region shown in Fig. 1 was obtained to be approximately $50 \mathrm{~m}^{2}$. Therefore, carbon accumulation in this region is estimated to be about $1 \mathrm{~g}$ and hydrogen accumulation is estimated to be $0.043-0.63$ mol- $\mathrm{H}_{2}$. When carbon adhesion in the roughing vacuum pump region following the region investigated in this work is taken into consideration, total amounts of carbon and hydrogen accumulation in whole exhaust system would increase more.

When $\mathrm{H}_{2}$ is replaced to $\mathrm{T}_{2}$ by using a conversion factor of $2.15 \times 10^{15} \mathrm{~Bq} / \mathrm{mol}_{-} \mathrm{T}_{2}$ without considerations of isotope effect and isotope mixing ratio in order to approximately evaluate tritium accumulation on the exhaust duct in a fusion reactor, the amount of tritium in this region is about $100 \mathrm{TBq}$ and $200 \mathrm{MBq} / \mathrm{cm}^{2}$. This amount is not ignorable from a viewpoint of tritium safety management although its amount would be significantly smaller than that in the vacuum vessel.

\section{Conclusions}

Carbon is uniformly accumulated with hydrogen on the metal wall of exhaust duct of LHD although its amount is significantly smaller than that in the vacuum vessel. The amount of carbon adhering to the metal wall is about $2 \mu \mathrm{g} / \mathrm{cm}^{2}$ and $\mathrm{H} / \mathrm{C}$ ratio is $1 \sim 1.5$. When total surface area of the duct wall in the region investigated is assumed to be $50 \mathrm{~m}^{2}$, carbon accumulation in the 13th campaign is about $1 \mathrm{~g}$ and hydrogen accumulation is about $0.043 \sim 0.063 \mathrm{~mol}-$ $\mathrm{H}_{2}$.

Hydrogen incorporated into the metal deposit formed from SS316 in the sputtering-deposition device in the laboratory can remain in the deposit under high vacuum condition in the exhaust duct for a long period.

\section{Acknowledgment}

This work was performed with the support and under the auspices of the NIFS Collaboration Research program (NIFS09KFSS014), and was partly supported by the JSPS-NRF-NSFC A3 Foresight Program in the field of Plasma Physics (NSFC: No.11261140328, NRF: No.2012K2A2A6000443).

[1] J. Roth and C. Hopf, J. Nucl. Mater. 334, 97 (2004).

[2] W. Jacob, J. Nucl. Mater. 337-339, 839 (2005).

[3] R.-D. Penzhorn et al., Fusion Eng. Des. 56-57, 105 (2001).

[4] A. Sagara et al., J. Nucl. Mater. 313-316, 1 (2003).

[5] Y. Nobuta et al., J. Nucl. Mater. 329-333, 800 (2004).

[6] M. Tokitani et al., J. Nucl. Mater. 417, 668 (2011).

[7] Y. Nobuta et al., J. Nucl. Mater. 438, S1040 (2013).

[8] T. Tanabe et al., J. Nucl. Mater. 345, 89 (2005).

[9] Y. Hirohata et al., J. Nucl. Mater. 363-365, 854 (2007).

[10] K. Katayama et al., J. Nucl. Mater. 438, S1010 (2013).

[11] Y. Uchida et al., Fusion Sci. Technol. 54, 545 (2008).

[12] K. Katayama et al., Fusion Eng. Des. 86, 1702 (2011).

[13] H.G. Esser et al., J. Nucl. Mater. 363-365, 146 (2007). 